\title{
Forest Crew Worker Electrocuted While Trying to Cut Tree Fallen on High-Voltage Power Line

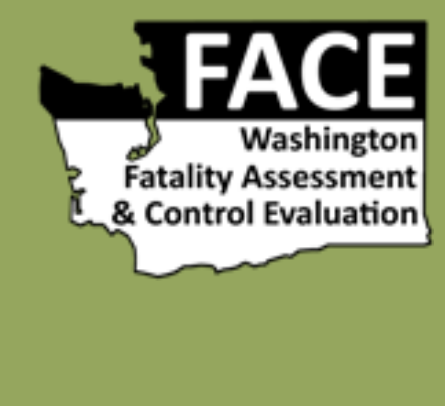

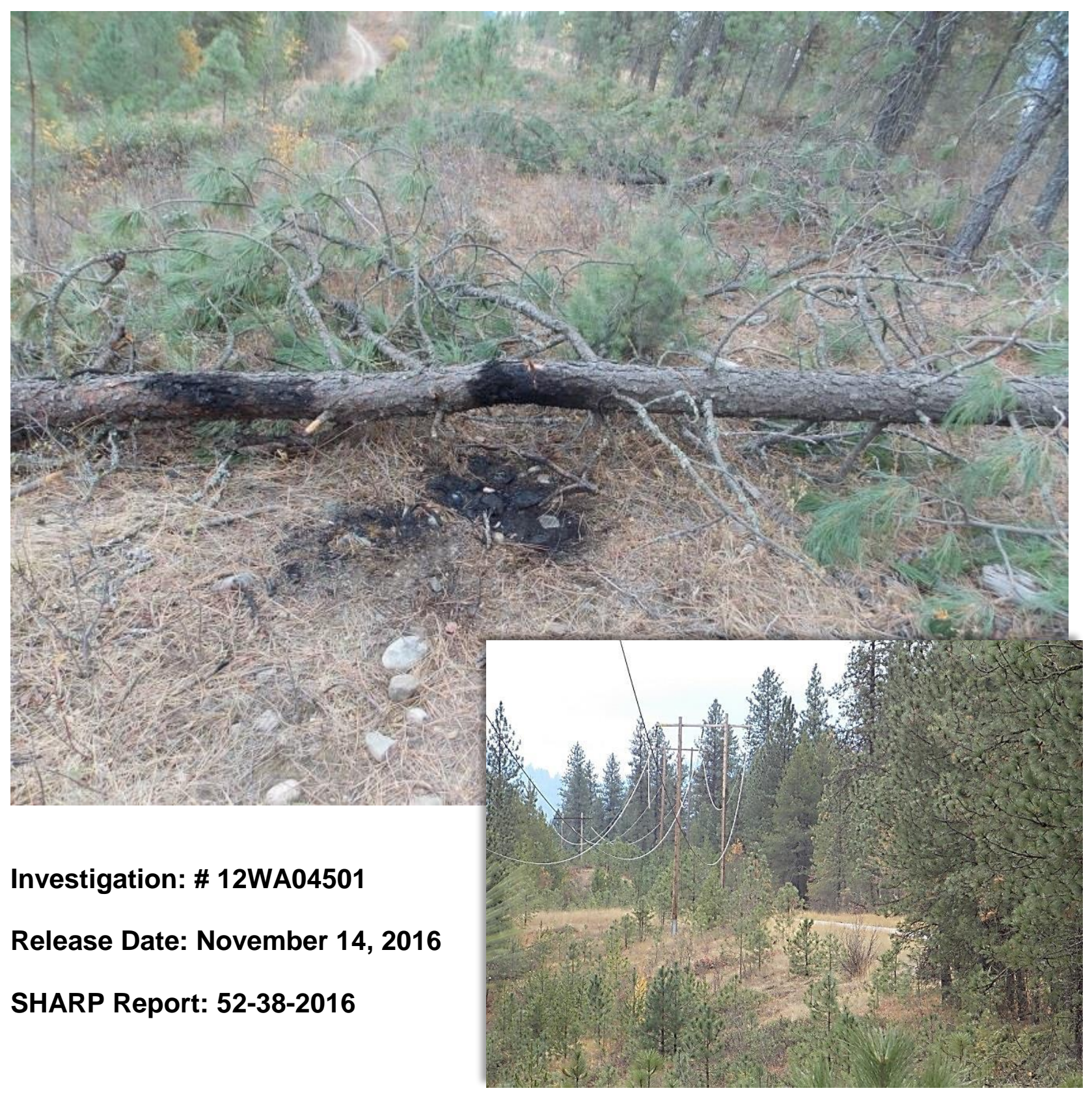




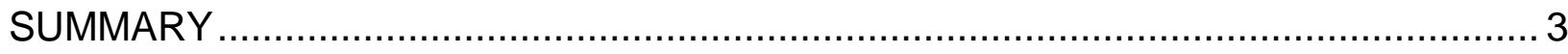

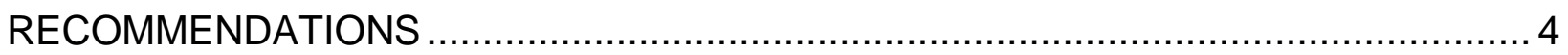

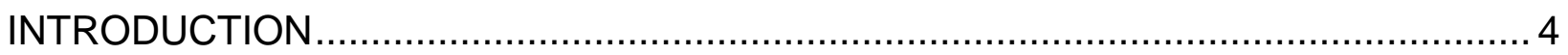

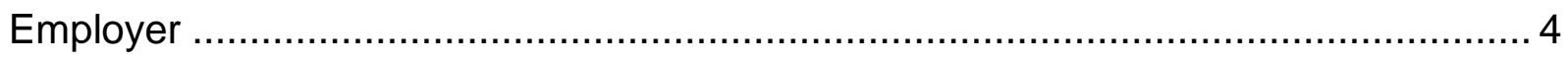

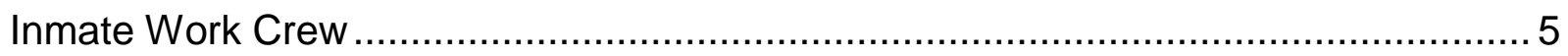

Employer Safety Training Program ............................................................. 5

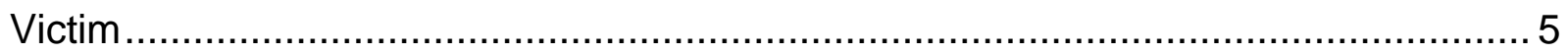

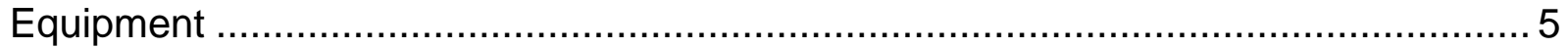

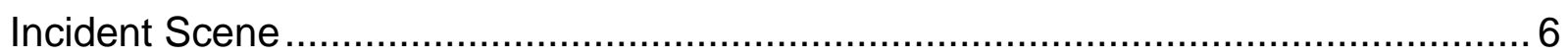

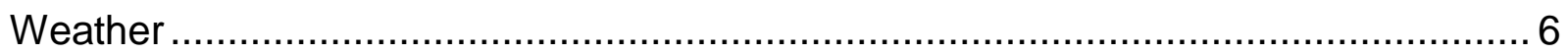

INVESTIGATION

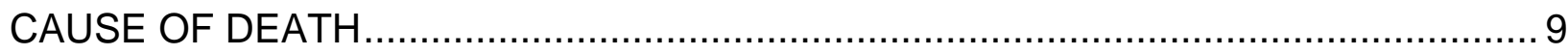

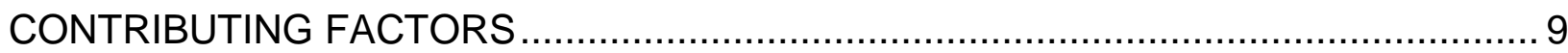

POST-INCIDENT CORRECTIVE ACTIONS TAKEN BY EMPLOYER ......................... 9

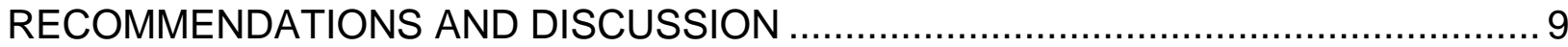

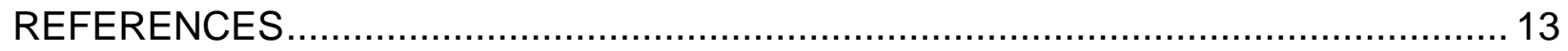

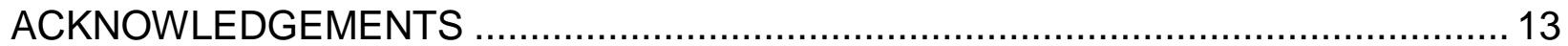

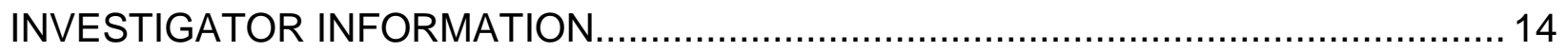

WASHINGTON STATE FACE PROGRAM INFORMATION ................................... 14 


\section{SUMMARY}

In October 2012, a 22-year-old worker on an inmate forest work crew was electrocuted while using a chainsaw to cut into a tree that had fallen onto an 115,000-volt power transmission line. The inmate work crew was employed by a state agency to conduct forest thinning on a plot of state owned land. The victim had been working with the crew for approximately 3 weeks before the incident. He had previously worked on a similar crew in another part of the state, and was generally considered the most experienced worker in the group.

At around 10:00 a.m., the forest crew supervisor conducted the on-site morning meeting. He discussed details of the work area and assignments, and some-site specific safety information, but no mention was made of the power transmission lines running through the work unit, or the risks and hazards associated with falling trees around overhead power lines. Following the meeting, the crew moved out in a line along the boundary of the site with their chainsaws to begin work. Around 11:00 a.m., the supervisor made a count of the crew and observed the victim and his partner thinning appropriate trees.

At approximately 11:30 a.m., the victim's work partner, who had been cutting up the trees that the victim fell, turned and saw that a large tree had fallen onto the nearest power line, and the victim was using his chainsaw to cut the tree while it was still leaning on the line. He saw that the victim was shaking and his feet appeared to be smoking, and ran to get help. Around the same time, the supervisor was informed by another crew member that a tree had been felled onto the power line. He looked and saw an electrical arc from the power line to the tree, and what appeared to be a worker shaking the tree. The supervisor shouted for the worker to get away from the tree. He reported hearing a loud noise, and seeing flames travel down the tree to the ground and the tree falling from the power line. As the supervisor went to his truck to notify dispatch of the incident, other workers hurried to the victim and found him burning, lying under the scorched tree, with severe burn injuries covering much of his body. They pulled the victim out from under the tree and put out the flames on his body with their drinking water. One worker attempted CPR, but it was apparent that the victim was deceased. When first responders arrived, they indicated that the victim had died from electrocution, and due to the extent of the injuries, no lifesaving measures would have been effective.

Investigators later found that the tree the victim felled was larger than the maximum size that the crew was allowed to cut, and it was outside of the work boundary. The direction of the face cut the victim had placed in the trunk led the tree to fall in a straight line toward the power lines, and no hinge wood had been left during cutting to guide the tree's fall. The victim had attempted to cut the tree from the power line with his chainsaw. He made one undercut successfully near the base of the tree, but, when that did not release the tree from the line, he attempted another cut further up the trunk and was electrocuted. 


\section{RECOMMENDATIONS}

To prevent similar incidents, Washington State Fatality Assessment and Control Evaluation (FACE) recommends that employers engaged in similar work:

- Develop, implement, and enforce a comprehensive written safety program that is tailored to the job, and includes safety information about all tasks employees will perform. Ensure that all forestry crew workers who will fall trees as part of their job, including temporary or seasonal workers, have successfully passed comprehensive job safety training before beginning work.

- Perform a thorough job hazard analysis (JHA) before work begins at each new worksite.

- Ensure that any worker who will be engaged in tree falling is thoroughly trained in directional cutting techniques.

- Ensure that there is competent supervision of workers during day-to-day operations.

\section{INTRODUCTION}

In October of 2012, The Washington State Division of Occupational Safety and Health (DOSH) notified the Washington State Fatality Assessment and Control Evaluation (FACE) program of the death of a 22-year-old inmate forest crew worker.

WA FACE investigators interviewed the safety manager for the state agency that had contracted the inmate work crew. Documents reviewed during the course of this FACE investigation include the DOSH investigation file, sheriff's office report, employer accident investigation documents, employer training documents and records, autopsy report, and death certificate.

\section{Employer}

The employer was a large Washington State agency that contracted minimum security prison work crews to do forestry work on state owned lands through an interagency agreement with the state Department of Corrections. This cooperative program has existed in some form in the state for over 60 years. The type of work the crews did was dependent on the season and could include wildland fire suppression, reforestation, vegetation management, and pre-commercial tree thinning. The employer provided 
specialized training and all onsite supervision for the work crews. Department of Corrections employees also provided some training for the inmates, as well as all transportation to and from the worksite, but were not present during work hours.

\section{Inmate Work Crew}

The ten-person inmate work crew was formed in mid-September 2012, approximately one month before the incident. Some training for the crew members had occurred in the month prior to that. The crew members are chosen by the Department of Corrections without input from the employing agency. The forest crew supervisor was a former corrections officer that had been working on a temporary appointment with the employer agency for approximately six months and supervising inmate work crews for five months.

\section{Employer Safety Training Program}

The employer uses a wildfire training curriculum developed by a group of national and state agencies. It is instructor led on a local level. Training would include in-class training and field assessment. Records show that the victim had received training regarding wildland fire suppression, as well as on-the-job training in chainsaw operation, but it is unclear if any of the training addressed hazards associated with tree falling or thinning work around overhead power lines. Records show that formal chainsaw training was not fully completed by the crew prior to the incident.

Due to the nature of inmate work crews, workers would join and leave work crews at different times with varying levels of training. Some may have already done similar work in the past, and others may have no prior experience.

\section{Victim}

The victim was a 22-year-old prison inmate working on a forestry crew. He had been working on the crew for approximately 3 weeks prior to the incident. He had been recently transferred from a correctional facility in another part of the state where he had done similar fire suppression and forestry work on an inmate crew there, including work with chainsaws. His pre-incarceration employment history was unknown. According to the employer, he was generally considered the most experienced member of the crew, and was designated by the supervisor as the 'lead' worker.

\section{Equipment}

The victim was using an unknown model Stihl chainsaw. The victim was wearing full personal protective equipment at the time of the incident, including work boots, safety glasses, hardhat and safety chaps. 


\section{Incident Scene}

The incident occurred on state-owned forest land between a rural road and a 60-foot power transmission right-of-way. The site was part of a unit where the crew had been performing pre-commercial tree thinning operations, and consisted mostly of Western Larch, Douglas Fir and Ponderosa Pine species. Part of the timber stand was at the top of a slope bordering the road (photo 1). The three 115,000-volt transmission lines ran along the base of the slope. It was approximately 45 feet from the tree line to the nearest power line (figure 1).

\section{Weather}

The weather at the time of the incident was dry and overcast. There had been little rain in the area in previous days.

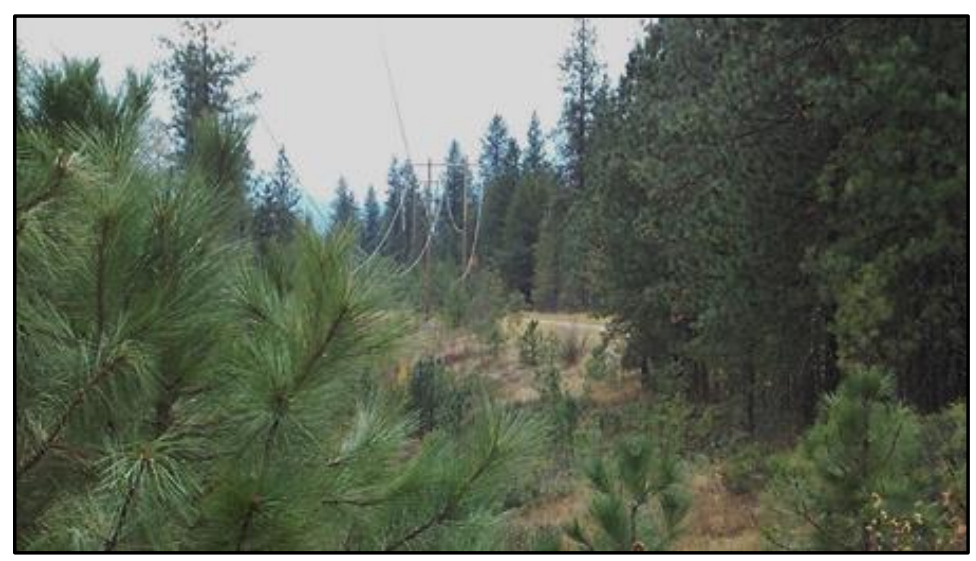

Photo 1: North to South view of stand of trees where victim was working and proximity to power lines.

Figure 1. Diagram of incident site

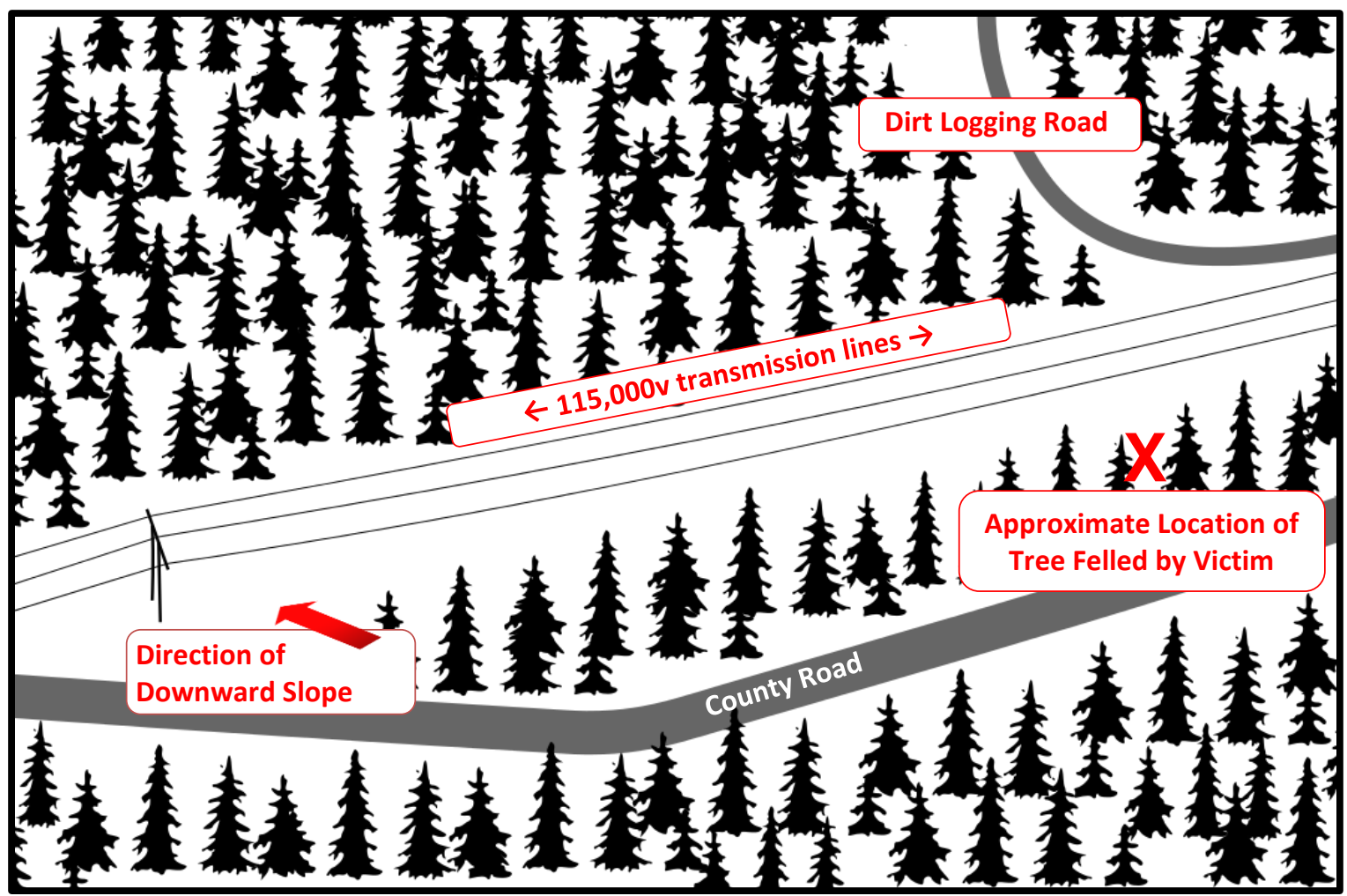




\section{INVESTIGATION}

On the morning of the incident, the ten-person inmate work crew and their forest crew supervisor arrived at the worksite just before 10:00 a.m. to conduct a pre-commercial thinning operation in a plot of state owned timber. Pre-commercial thinning involves reducing the density of a commercial stand of timber by removing some trees before they reach saleable size in order to increase the growth of the remaining trees. For this operation, the crew had been instructed to only fall trees within a specific perimeter that were up to 8 inches diameter breast height (dbh); the diameter at 4 feet from the base of the tree. Workers estimated dbh in the field without taking formal measurements. The trees were to be cut manually using powered chain saws.

The crew unloaded their equipment near the center of the work area near the road, and the supervisor conducted a morning meeting. The meeting covered details of the work area and assignments, and some site specific safety information, but no mention was made of the power transmission lines running through the unit, or the risks and hazards associated with falling trees around overhead power lines.

Following the meeting, at about 10:15 a.m., the crew began to move out in a line along the boundary of the site with their chainsaws to begin work. The supervisor and another worker left to mark the northern boundary of the worksite. Four days earlier, the employer's camp manager visited the site and found that the crew had been falling trees outside of the unit boundary. At that time, the camp manager showed the supervisor the correct unit boundary and reiterated that the crew was only to cut within that perimeter. The camp manager did not identify the power lines as a hazard when he visited the site. The crew supervisor stated that when he conducted a mandatory count of the crew at 11:00 a.m. he saw the victim and his work partner thinning appropriate trees between the road and the power line right-ofway.

The victim was working falling trees within the stand adjacent to the road at the top of the slope (photo 2). His partner was working with his back to the victim, bucking the trees felled by the victim into smaller pieces. After finishing cutting one tree into sections, the victim's partner turned and noticed the top of a

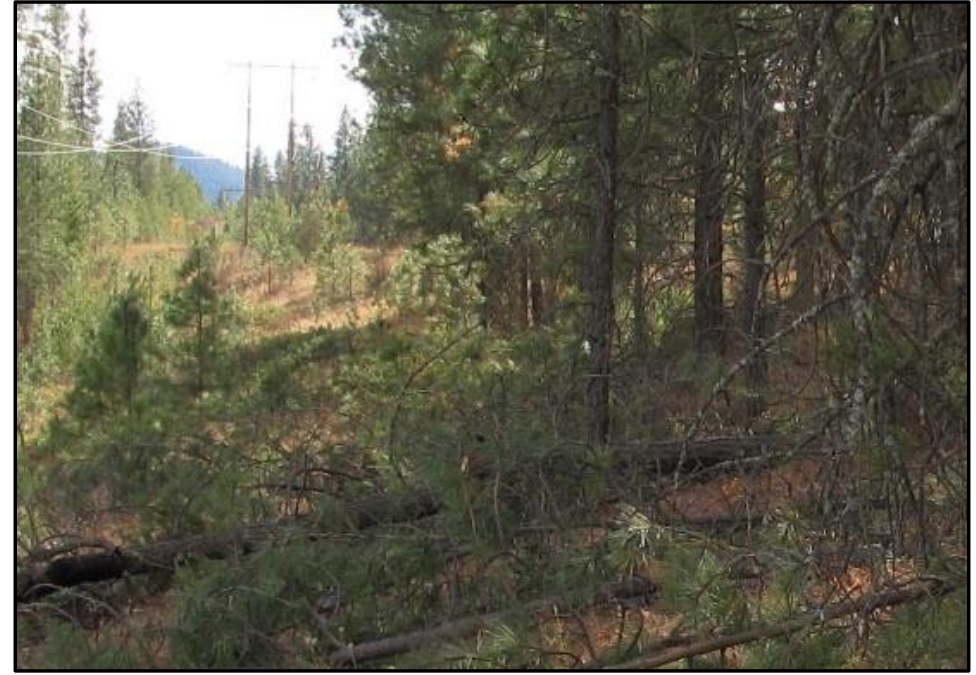

Photo 2: Tree felled by victim, showing stand of trees and power lines. 


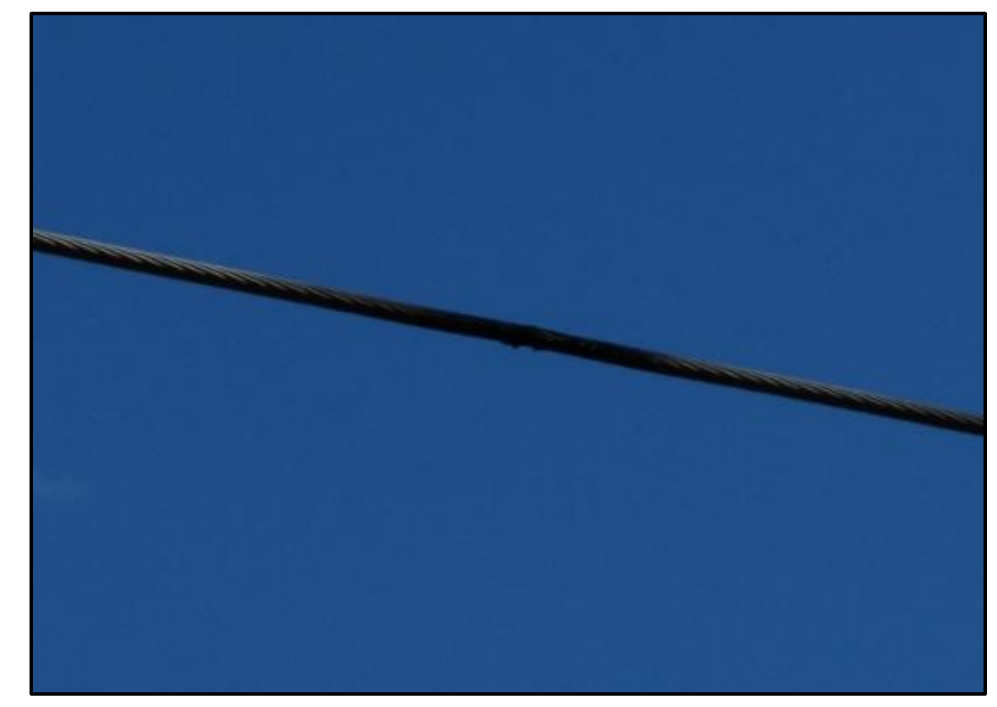

Photo 3: Burn damage on power line where tree fell onto it tree leaning on one of the power lines. He could see the victim from behind, apparently trying to undercut the tree. The victim was shaking and his feet appeared to be smoking. He ran toward the victim, but stopped when he realized the victim was being electrocuted. The partner yelled and ran for help. He did not hear a response from the supervisor, but noticed someone cutting firewood alongside the road and asked them to call 911.

Around this time, the supervisor had been notified by other workers that a tree had fallen on the line. He looked and saw a tree caught on the power line and what appeared to be a worker shaking the tree. He heard a loud "pop" and saw an electrical arc from the power line to the tree. Flames travelled down the tree and the ground at the base of the tree caught fire. The tree fell from the power line. He yelled for workers to get away from the tree and to return to the work truck to get their fire suppression supplies. The supervisor tried to make an emergency call on his hand-held radio, but reception was not clear. He then drove the work truck back up to the county road and made the call on the truck radio.

By this time, other workers had gotten to the victim and found him pinned under the fallen tree with his clothes burning. They used their drinking water to try to extinguish the flames, and one worker began CPR. When it was apparent that the victim was deceased, they moved his body closer to the road to await emergency responders.

Investigators later found that the victim had made one cut without incident through the tree approximately 11 feet from the base of the tree in his attempt to remove the tree from the power line. When the tree remained

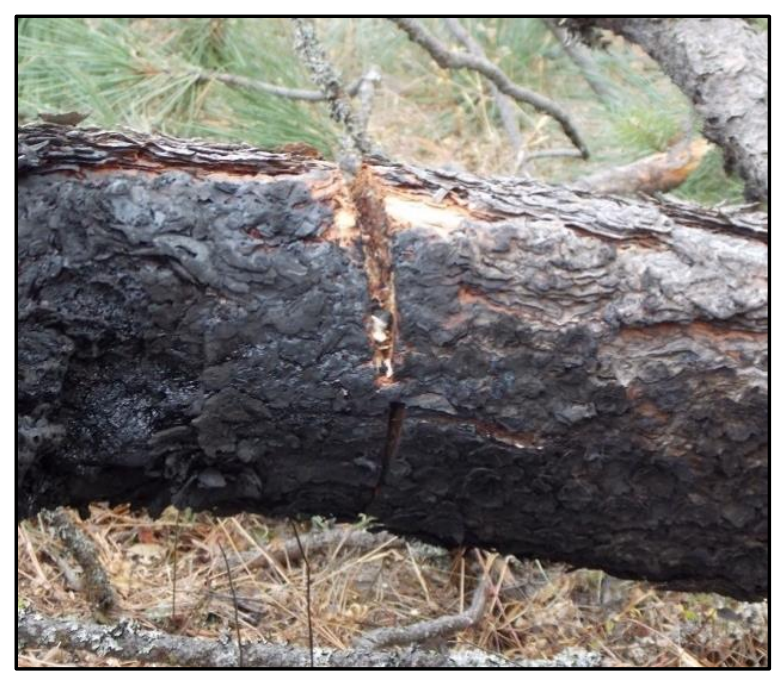

Photo 4: Top and bottom cuts on tree at location where electrocution occurred hung-up after this cut, he moved 9 feet further up the trunk and made cuts to the top and bottom of the tree (photo 4). It was as he was making one of these cuts that the tree became energized and created a path to ground through the victim. 


\section{CAUSE OF DEATH}

The medical examiner reported that death was caused by electrocution. Postmortem toxicology was negative for drugs and alcohol.

\section{CONTRIBUTING FACTORS}

- Lack of awareness of high voltage hazards posed by power transmission lines

- Lack of competent supervision on site

- Lack of knowledge of how electrical currents are conducted

- Crew did not know/ follow work perimeter guidelines

- Crew was cutting trees that were too large

- Lack of knowledge of proper tree falling techniques

\section{POST-INCIDENT CORRECTIVE ACTIONS TAKEN BY EMPLOYER}

Following this incident, the employing agency began to require that a comprehensive risk assessment be done prior to work on all pre-commercial thinning jobsites, including a check-list of potential hazards to look for, as well as control measures to apply when specific risks were found. They also directed that no tree thinning work would be done by inmate work crews within two tree-lengths of the tallest trees in the stand and power lines; this work would be contracted out to companies with specialized high voltage training. A new training course in chainsaw use was developed that specifically addressed the hazards of manual tree falling and included working around power lines.

The agency also implemented new rules for supervisors on pre-commercial thinning sites, requiring that they maintain "line of sight" monitoring of crews and that regular walk-throughs are done to ensure that workers are using proper falling techniques.

\section{RECOMMENDATIONS AND DISCUSSION}

Recommendation 1: Develop, implement, and enforce a comprehensive written safety program that is tailored to the job, and includes safety information about all tasks employees will perform. Ensure that all forestry crew workers who will fall trees as part of their job, including temporary or seasonal workers, have successfully passed comprehensive job safety training before beginning work. 
Discussion: Employers must provide safety training to each employee that includes information about the hazards associated with worker's specific job tasks. Safety training for forest crew workers should specifically provide information about understanding, identifying, and avoiding high voltage hazards during tree thinning and falling operations, including:

- Maintaining a minimum clearance distance, based on voltage, between power lines and any part of a tree as it is being fell. A minimum clearance distance of ten feet at line voltages of $50 \mathrm{kV}$ or below, and farther at higher voltages, is required by the Washington Administrative Code (table 1). The Washington State Logger Safety Initiative recommends maintaining a minimum clearance of fifteen feet between overhead electrical lines and all trees being fell.

- Directionally falling all trees away from power lines

Table 1. Required minimum overhead electrical lines clearance during logging operations, WAC 296-54-529

\begin{tabular}{|l|l|}
\hline Line Voltage & $\begin{array}{l}\text { Required minimum clearance between lines and any part of } \\
\text { equipment or machine }\end{array}$ \\
\hline $50 \mathrm{kV}$ or below & Ten feet \\
\hline Over $50 \mathrm{KV}$ & $\begin{array}{l}\text { Ten feet plus } 0.4 \text { inch for each } 1 \mathrm{kV} \text { over } 50 \mathrm{kV} \text {, or twice the } \\
\text { length of the line insulator, but never less than ten feet. }\end{array}$ \\
\hline
\end{tabular}

In this incident, the tree line of the stand of trees in which the victim was working was approximately 45 feet from the nearest of the three power lines. The tree that the victim fell on the line was approximately 58 feet in length; much taller than would allow at least 15 feet of clearance between the line and the tree as it fell. Investigators also found that the face cut made in the tree aimed the direction of fall at the power lines. Had he received thorough safety training regarding falling trees near power lines, it is possible that the victim would have recognized and avoided the hazard.

Safety training should also instruct workers what to do in the event that a tree falls onto a power line, including:

- Avoid any contact with the tree or any downed power lines

- Immediately clear the area and remain at a safe distance

- Call the utility company that owns the lines to inform them of the incident

When the tree he was falling became hung-up on the power line, the victim attempted to remove it by cutting it using his chainsaw. Without specific training, workers may not come to a job with knowledge of how electricity is conducted through power lines, what 
types of materials readily conduct electricity, and how electric shocks can occur. Safety training for workers who may be exposed to high voltage hazards should include such important basic background information about electricity, in addition to how to avoid exposure. In this incident, the victim's attempt to cut a fallen tree off of a live power distribution line made clear that he was unaware of the danger of electrocution in that situation. Other members of the work crew also told investigators that they were not aware that trees could conduct electricity. If information about high voltage hazards had been effectively communicated to the crew, the victim may not have attempted to remove the tree from the line himself.

In this case, after the fallen tree became energized and the victim was electrocuted, it fell from the power line. By the time the victim's coworkers reached him, electricity was no longer flowing from the line to ground at the site. However, if other workers were unaware of the hazard of electrical shock and had attempted to approach or touch the victim or tree while the tree was energized, more injuries or deaths may have occurred.

The forest crew working on the day of the incident was comprised of prison inmates. Crew members could be assigned to work crews at different times during the season and could have differing levels of experience and training in tree falling techniques. Most members of the crew had completed much of the employing agency's wildland firefighting training, but had not completed comprehensive chainsaw training. A similar situation might occur for employers that hire temporary or seasonal workers during busy seasons. It is important that all forestry crew workers be fully trained before being allowed to do tree thinning or falling in the field.

Recommendation 2: Perform a thorough job hazard analysis (JHA) before work begins at each new worksite.

Discussion: An effective JHA should break down a job into the sequence of tasks that will be performed, identify the potential hazards associated with each task, including environmental hazards, and provide hazard control measures. The JHA should be developed in collaboration with the work crew. If the work to be done at each jobsite is similar, such as forest thinning, a checklist could be created to look for common hazards, such as overhead power lines. Results and recommendations of the JHA should be shared with workers prior to beginning work on the job, with markers such as flags or tape indicating hazards when appropriate. Supervisors should follow through with workers to make sure safety procedures are followed.

Prior to this incident, the employer did not perform a job hazard analysis or survey the site for environmental hazards before starting work on a new unit. In this case, the crew supervisor had not recognized the power lines as a hazard, and did not mention them at the pre-work safety meeting on the morning of the incident. His manager had likewise 
failed to identify the power lines as a hazard when he had visited the site on an earlier occasion. Some crew members told investigators that they had not noticed the power lines.

A formal job hazard analysis could have identified the overhead power lines as an environmental hazard that crew members may be exposed to during the task of tree thinning. The utility company should have been contacted to determine the precise voltage of the power lines. Measures could then have been taken to make the crew aware of the hazard, and to reduce or eliminate the exposure by designating and marking a work boundary taking into account safe clearance distances.

Recommendation 3: Ensure that any worker who will be engaged in tree falling is thoroughly trained in directional cutting techniques.

Discussion: Investigators determined that the victim had not been using safe cutting practices to control the direction of tree fall away from the hazard of the power lines. The undercut that the victim made in the tree involved in the incident was facing downhill toward the power lines, causing the tree to fall in that direction.

Also, in several instances, the victim and at least one other worker had not left enough hinge wood (also called holding wood) when a tree was cut. Leaving sufficient hinge wood between the undercut and the backcut is necessary to maintain directional control of a tree being fell. It holds the tree to the stump and guides the tree in the intended direction as it falls. If not enough hinge wood is left, a tree could break or twist off the stump and fall in the wrong direction.

Before beginning to cut timber, workers should receive comprehensive training in how to safely maintain directional control of trees being felled, including hands-on field instruction.

Recommendation 4: Ensure that there is competent supervision of workers during dayto-day operations.

Discussion: Supervisors need to be experienced in the type of work that forest crew workers will be doing, including tree falling techniques, and must regularly inspect the work of the crew to ensure it is being done in a safe manner. In this case, the supervisor on site had been trained in chainsaw operations, but was unaware of minimum approach distances when working around power lines.

The incident tree felled by the victim was found to have insufficient hinge wood, was cut outside of the work boundary, and was larger than prescribed to be cut. Supervisors 
need to regularly assess the work that the crew is doing to ensure that they are using safe methods and correct unsafe practices.

Supervisors should promote a safety climate where workers are encouraged to report errors, and do not engage in risky behavior to try to correct an error themselves. It is unknown why the victim attempted to cut the fallen tree from the line himself instead of alerting his supervisor. Workers should be regularly reminded that safety is the priority when errors do occur.

\section{REFERENCES}

1. Weather Underground. Weather History for KDEW - October 2012 www.wunderground.com/history/airport/KDEW/2012/10/23/MonthlyCalendar

2. Washington Logger Safety Initiative. Approved Cutting Operations Accident Prevention Program. www.Ini.wa.gov/main/loggersafety/PoliciesTraining.asp

3. Washington Administrative Code Chapter 296-54, Safety Standards - Logging Operations. apps.leg.wa.gov/WAC/default.aspx?cite $=296-54$

4. U.S. Department of Labor Occupational Safety and Health Administration [OSHA]. (2002). Job Hazard Analysis Guide. Publication number: OSHA 3071 www.osha.gov/Publications/osha3071.html

5. Oregon Fatality Assessment and Control Evaluation. Fallers Logging Safety manual 2007. www.ohsu.edu/xd/research/centers-institutes/oregon-institute-occupational-healthsciences/outreach/or-face/publications/upload/FallerSafety web rev Feb08.pdf

6. WorkSafeBC. BC Faller Training Standard. www.worksafebc.com/en/healthsafety/education-training-certification/faller

\section{ACKNOWLEDGEMENTS}

This report was reviewed by stakeholders from labor and business communities and various Washington State and Federal worker safety agencies. Though we are unable to acknowledge specific individuals for their contributions to this report, we would like to recognize the following for their help and support of the FACE mission and objectives:

- The Employer involved in the incident

- Safety \& Health Assessment \& Research for Prevention (SHARP)

- Division of Occupation Safety and Health (DOSH)

- Federal FACE Program Management (NIOSH) 


\section{INVESTIGATOR INFORMATION}

Todd Schoonover has a PhD in Industrial Hygiene from the University of Illinois at Chicago. He is a Certified Industrial Hygienist $(\mathrm{ClH})$ and Certified Safety Professional (CSP). Todd is currently the Principal Investigator for the WA FACE program.

Randy Clark has a BA from The Evergreen State College. He is a Safety and Health Specialist with the WA FACE program.

Christina Rappin has a BA/BS from The Evergreen State College. She is a Research Investigator with the WA FACE program.

\section{WASHINGTON STATE FACE PROGRAM INFORMATION}

The Washington State Fatality Assessment and Control (WA FACE) program is one of many workplace health and safety programs administered by the Washington State Department of Labor \& Industries' Safety \& Health \& Research for Prevention (SHARP) program. Under a cooperative agreement with the National Institute for Occupational Safety and Health (NIOSH grant\# 2U60OH008487-11), WA FACE collects information on occupational fatalities in WA State and targets specific types of fatalities for evaluation. WA FACE investigators evaluate information from multiple sources. Findings are summarized in narrative reports that include recommendations for preventing similar events in the future. These recommendations are distributed to employers, workers, and other organizations interested in promoting workplace safety. NIOSH-funded, statebased FACE programs include: California, Kentucky, Massachusetts, Michigan, New York, Oregon, and Washington. WA FACE does not determine fault or legal liability associated with a fatal incident. Names of employers, victims and/or witnesses are not included in written investigative reports or other databases to protect the confidentiality of those who voluntarily participate in the program.

Additional information regarding the WA FACE program can be obtained from:

Washington State FACE Program

www.Ini.wa.gov/safety/research/face/

PO Box 44330

Olympia, WA 98504-4330

1-888-667-4277 